\title{
A Rare Case of a Discal Cyst Following Percutaneous Endoscopic Lumbar Discectomy via a Transforaminal Approach
}

\author{
HIROAKI MANABE, MD, KOSAKU HIGASHINO, MD, PhD, KOSUKE SUGIURA, MD \\ Orthopedic Surgery, Takamatsu Municipal Hospital, Takamatsu City, Kagawa, Japan
}

\begin{abstract}
A discal cyst is a rare lesion that causes low back pain and radiculopathy of the lower extremities. There are several reports of discal cysts occurring after surgery, but data are limited on their occurrence after percutaneous endoscopic discectomy (PED). A 21-year-old man with disc herniation at the L4-L5 disc level underwent PED via a transforaminal approach. The immediate postoperative course was uneventful and his symptoms were relieved. Six weeks after surgery, low back pain and mild pain in the left thigh recurred. Magnetic resonance imaging (MRI) revealed a cystic lesion adjacent to the left side of the L4-L5 intervertebral disc. Conservative treatment was ineffective, so we reoperated using PED with the same approach. Pain improved and MRI revealed disappearance of the cystic lesion. When symptoms relapse after PED, it is necessary to consider the occurrence of a cyst.
\end{abstract}

Endoscopic Minimally Invasive Surgery

Keywords: discal cyst, lumbar disc herniation, percutaneous endoscopic lumbar discectomy, transforaminal approach

\section{INTRODUCTION}

Discal cysts are defined as extradural masses that communicate with the intervertebral disc. ${ }^{1}$ The pathogenesis and etiology are still unclear. Many reports describe discal cysts occurring in the intraspinal extraepidural area that communicate with the corresponding intervertebral discs. Several reports have described discal cysts occurring after lumbar discectomy via posterior approaches, such as conventional open discectomy, the technique described by Love, or microendoscopic discectomy. ${ }^{2-4}$

Here, we report the rare case of a discal cyst that developed after percutaneous endoscopic lumbar discectomy (PED) via a transforaminal approach.

\section{CASE REPORT}

A 21-year-old man visited our hospital with intolerable low back pain and numbness of the left lower leg for 3 months. Despite conservative treatment, his symptoms worsened. Preoperative physical examination with the straight-leg-raising tests showed that movement of the left leg was restricted to $20^{\circ}$. Manual muscle testing of the left extensor hallucis longus and the left tibialis anterior was grade 4. Magnetic resonance imaging (MRI) showed disc herniation on the left side of L4-L5 (Figure 1).

PED via a transforaminal approach was performed under local anesthesia. Closed suction drainage was used for 24 hours after surgery. Immediately after surgery, the low back pain and left leg numbness subsided. Postoperatively, straight-leg-raising tests improved to $70^{\circ}$, without pain. He returned to work 3 weeks after surgery. However, low back pain and mild left leg pain recurred 6 weeks after surgery. MRI revealed a cystic lesion adjacent to the left side of the intervertebral disc at L4-L5 that was communicating with the approach site following percutaneous endoscopic cannula insertion. MRI T1-weighted images showed low signal intensity, and T2-weighted images showed high signal intensity (Figure 2). We made a diagnosis of postoperative discal cyst communicating with the approach site following percutaneous endoscopic cannula insertion.

The discal cyst was imaged using iodine-containing contrast medium. The patient was noted to have referred pain (Figure 2). We injected $2 \mathrm{~mL}$ of $1 \%$ xylocaine with dexamethasone into the discal cyst, and the symptoms were relieved. He was able to 

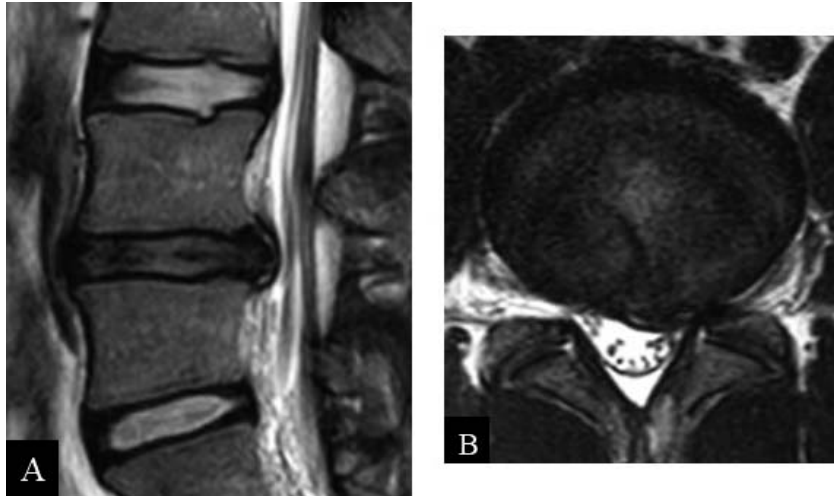

Figure 1. Preoperative T2-weighted magnetic resonance imaging (MRI) (sagittal view) shows disc herniation at the L4-L5 disc level (A) and axial view of MRI shows left side herniation (B).

return to work, but he subsequently experienced severe low back pain again during physical activity 2 weeks after the injection.

We planned the revision PED under local anesthesia. There was no pain noted after insertion of the needle, with the tip positioned longitudinally in the middle of the disc at L4-L5. He reported low back pain after insertion of the $8-\mathrm{mm}$ cannula. We performed foraminoplasty to avoid irritation of the exiting nerve root. Using the inside-out technique and hand-down technique to visualize the discal cyst, we curetted the discal cyst completely.

Low back pain and lower limb pain improved immediately after revision surgery. Follow-up MRI showed no recurrence of the discal cyst at L4-L5 (Figure 3), and he had a full return to work.

\section{DISCUSSION}

Although discal cysts have been reported to occur in the intraspinal extraepidural area, ${ }^{1,2,5}$ this is a rare case caused by the entry pathway of the PED on the intervertebral disc. The pathogenesis and
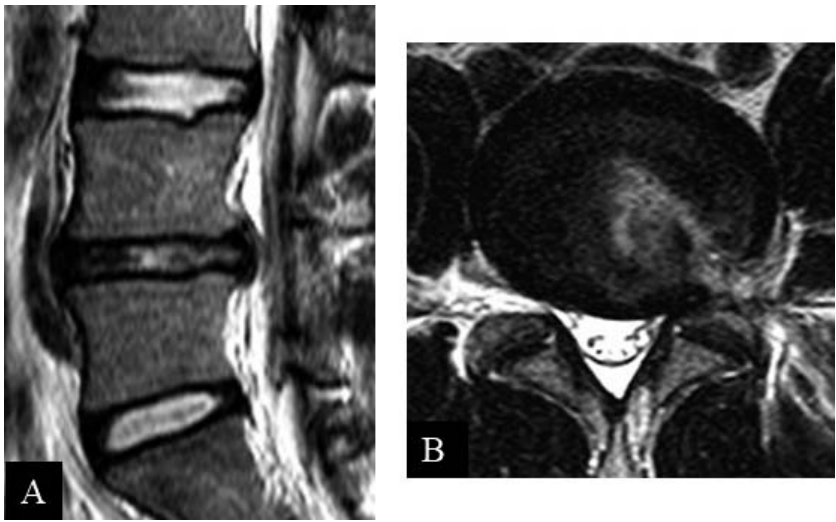

Figure 3. At 5 days after revision percutaneous endoscopic discectomy (PED) surgery, the discal cyst disappeared on T2-weighted magnetic resonance imaging $(A)$ sagittal and $(B)$ axial views.

etiology are still unclear. Chiba et $\mathrm{al}^{6}$ reported that the cyst wall consists of dense fibrous connective tissue containing bloody to clear serous discharge and suggested that underlying minor disc injury may serve as a basis for cyst formation. Kono et $\mathrm{al}^{7}$ noted that a discal cyst results from focal degeneration and cystic softening of collagenous connective tissue of the disc with fluid production, similar to the mechanism of meniscal cysts in the knee. There are several reports ${ }^{1,8}$ that histopathological findings show predominantly fibrous connective tissue without synovial lining cells.

MRI and discography allow discal cysts to be diagnosed easily. ${ }^{1,9}$ In our case, we diagnosed the cyst on the basis of MRI findings that clearly showed the relation of the lesion to the approach site following percutaneous endoscopic cannula insertion.

The pathogenesis of the discal cyst outside the spinal canal is unclear. PED performed using normal saline may have caused the lesion. Although there are a few reports of lesions that resolved with
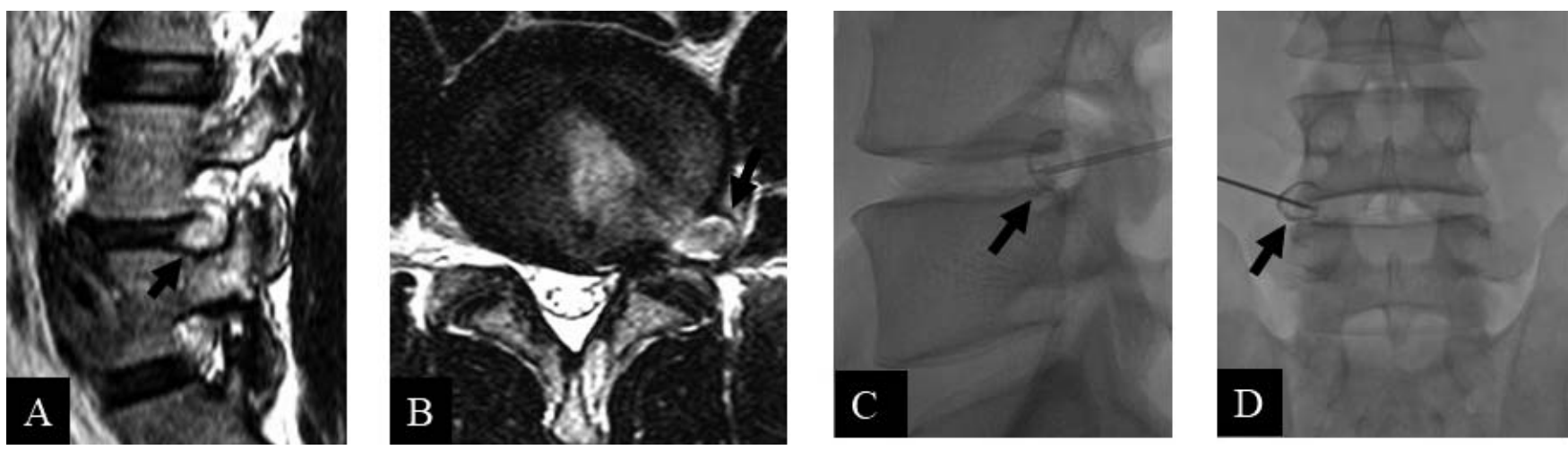

Figure 2. Postoperative radiographic findings at 6 weeks show a cystic lesion on the left side of L4-L5 disc on T2-weighted magnetic resonance imaging (A, B) and enhancement of the mass on contrast radiography $(C, D)$. 
conservative therapy, good outcomes and low recurrence rates have been obtained in most cases through aspiration and surgical treatment, such as microendoscopic discectomy and PED. ${ }^{5,10,11}$

Although it is possible that PED will not be able to completely resect the cyst, symptoms may be alleviated by decompression of the cyst contents and the intervertebral disc. Furthermore, the potential for recurrence can be reduced by annuloplasty using radiofrequency coagulation. ${ }^{12,13}$

\section{CONCLUSION}

We have reported a rare case of a discal cyst that developed after percutaneous endoscopic lumbar discectomy via a transforaminal approach. We consider PED to be a useful technique for lumbar discal cysts that develop after surgery, using both the posterior approach and the transforaminal approach for lumbar discectomy.

\section{REFERENCES}

1. Aydin S, Abuzayed B, Yildirim H, Bozkus H, Vural M. Discal cysts of the lumbar spine: report of five cases and review of the literature. Eur Spine J. 2010;19(10):1621-1626.

2. Jha SC, Tonogai I, Higashino K, et al. Postoperative discal cyst: an unusual complication after microendoscopic discectomy in teenagers. Asian J Endosc Surg. 2016;9(1):89-92.

3. Chung D, Cho DC, Sung JK, Choi E, Bae KJ, Park SY. Retrospective report of symptomatic postoperative discal pseudocyst after lumbar discectomy. Acta Neurochir (Wien). 2012;154(4):715-722.

4. Young PM, Fenton DS, Czervionke LF. Postoperative annular pseudocyst: report of two cases with an unusual complication after microdiscectomy, and successful treatment by percutaneous aspiration and steroid injection. Spine J. 2009;9(2):e9-e15.

5. Yu HJ, Park CJ, Yim KH. Successful treatment of a symptomatic discal cyst by percutaneous c-arm guided aspiration. Korean J Pain. 2016;29(2):129-135.

6. Chiba K, Toyama Y, Matsumoto M, Maruiwa H,
Watanabe M, Nishizawa T. Intraspinal cyst communicating with the intervertebral disc in the lumbar spine: discal cyst. Spine (Phila Pa 1976). 2001;26(19):2112-2118.

7. Kono K, Nakamura H, Inoue Y, Okamura T, Shakudo M, Yamada R. Intraspinal extradural cysts communicating with adjacent herniated disks: imaging characteristics and possible pathogenesis. AJNR Am J Neuroradiol. 1999;20(7):1373-1377.

8. Murata K, Ikenaga M, Tanaka C, Kanoe H, Okuaaira S. Discal cysts of the lumbar spine: a case report. J Orthop Surg (Hong Kong). 2007;15(3):376-379.

9. Lee HK, Lee DH, Choi CG, et al. Discal cyst of the lumbar spine: MR imaging features. Clin Imaging. 2006;30(5):326-330.

10. Kim JS, Choi G, Lee CD, Lee SH. Removal of discal cyst using percutaneous working channel endoscope via transforaminal route. Eur Spine J. 2009;18(suppl 2):201-205.

11. Jha SC, Higashino K, Sakai T, et al. Percutaneous endoscopic discectomy via transforaminal route for discal cyst. Case Rep Orthop. 2015;2015:273151.

12. Ha SW, Ju CI, Kim SW, Lee S, Kim YH, Kim HS Clinical outcomes of percutaneous endoscopic surgery for lumbar discal cyst. J Korean Neurosurg Soc. 2012;51(4):208214.

13. Sairyo K, Kitagawa Y, Dezawa A. Percutaneous endoscopic discectomy and thermal annuloplasty for professional athletes. Asian J Endosc Surg. 2013;6(4):292-297.

Disclosures and COI: The authors received no funding for this study and report no conflicts of interest.

Corresponding Author: Kosaku Higashino MD, PhD, 3-18-15 Kuramoto-cho, Tokushima 7708503, Japan. Phone: +81-88-633-7240; Fax: +81-88633-0178; Email: kosahigaisno@gmail.com.

Published 22 February 2019

This manuscript is generously published free of charge by ISASS, the International Society for the Advancement of Spine Surgery. Copyright (c) 2019 ISASS. To see more or order reprints or permissions, see http://ijssurgery.com. 